\title{
Significant implication of unified power quality conditioner in power quality problems mitigation
}

\author{
Kamrul Hasan', Muhammad Murtadha Othman², Nor Farahaida Abdul Rahman ${ }^{3}$, M. A. Hannan ${ }^{4}$, \\ Ismail Musirin 5 \\ 1,2,3,5 Faculty of Electrical Engineering, Universiti Technologi MARA, 40450 Shah Alam, Selangor, Malaysia. \\ ${ }^{4}$ Department of Electrical Power Engineering, College of Engineering, Universiti Tenaga Nasional, 43000, Malaysia
}

\section{Article Info \\ Article history: \\ Received Mar 21, 2019 \\ Revised Jul 14, 2019 \\ Accepted Jul 31, 2019 \\ Keywords: \\ Power Quality \\ Series compensator \\ Shunt compensator \\ UPQC}

\begin{abstract}
This paper presents an analysis of a three-phase unified power quality conditioner (UPQC) in terms of design and performance. A back to back connection of a series compensator and a shunt compensator with a common DC-bus is utilized to build the UPQC model. The series compensator compensates the power quality problems such as grid voltage sags/swells for the grid side. During sag and swell condition, the compensated voltage is injected by the series compensator in phase with the point of common coupling (PCC) or out of phase with PCC. The load current harmonics is compensated by using the shunt compensator. The dynamic performance and the steady state of the designed model are analyzed by using MATLABSimulink under several disturbances such as PCC voltage harmonics, voltage sags/swells and load unbalancing using a nonlinear load.
\end{abstract}

Copyright ( 2019 Institute of Advanced Engineering and Science. All rights reserved.

\section{Corresponding Author:}

Muhammad Murtadha Othman

Faculty of Electrical Engineering, Universiti Teknologi MARA, 40450 Shah Alam, Selangor, Malaysia. Email:mamat505my@yahoo.com

\section{INTRODUCTION}

The basic input of life relies on different form of energy. Electricity is a sign of flexible life and this energy source demand is expanding rapidly. A smooth supply of the electrical energy must be ensured stringently by mitigating the power quality issues to utilize this energy efficiently. Power quality is a comprehensive expression which comprehends different categories of disturbances related to voltage and current such as harmonic current, voltage sag/swell, voltage unbalance, flicker and low-quality power factor etc. The penetration of power electronic loads has been increased due to the rapid advancement of power industries. Among these loads, large variable frequency drives (VFD), arc furnaces and heavy rectifiers are the loads utilized in the industry and they draw non-linear currents from the AC grid. Nowadays, harmonics problems are widespread not only in industrial applications but in commercial building as well. This is due to the new power conversion technologies utilized regularly like switch mode power supply (SMPS) that can be observed in power electronic devices such as computers, printers, servers and so on. These power electronics devices generate non-linear currents which are responsible for voltage distortion at the PCC specifically in the distribution system. The voltage quality issues are responsible for additional heating on capacitor banks, false triggering electronic system, malfunctioning and so on [1-3]. Modern distribution systems are facing major issues regarding the power quality problems at grid part and load part. Since the latest domestic and industrial components respond critically to voltage disturbances, the equipment can be terminated for a short period of voltage sag which results complete termination of an industrial process. Therefore, power quality compensation turned to be an unavoidable requirement in the distribution system [4]. The power companies and the researchers are extensively investigating the solutions to power quality problems [5]. Flexible AC 
transmission system (FACTS) devices, for instance active power filters (APFs) and the static compensators (STATCOMs) are one of the leading technologies convenient for the commercial and industrial purposes. These FACTS devices are considered to solve these power quality problems [6-8].

Passive filters (PFs) were used to solve the harmonic grid problem for many years [9]. PFs with reduced cost solution of power quality problems, are regarded as the preliminary progress of the compensation of the current harmonics $[10,11]$. The next stage of progress is the utilization of APFs which solved the drawbacks of PFs significantly. The utilization of shunt APF has been an efficient technique to compensate power quality problems. Although, shunt APF can regulate load voltage, but it injects reactive power. Therefore, the shunt APF is not capable of regulating PCC voltage and also fails to maintain unity power factor for the grid current. Hybrid power filter (HPF) is the later development, which is a combination of shunt APFs with PFs. However, the power system capacity demand is increasing, so the rating, size and the cost of APFs are significantly expanded.

According to the IEEE 519 [12] standard, several custom power devices are introduced [13-17]. These devices are designed to be installed in the consumer side to surpass the power quality problems. Since the sensitive loads have higher voltage quality requirements, the series APFs have been utilized in the commercial buildings and small apartments $[18,19]$. In comparison with shunt and series APFs, UPQC is constructed with a series and parallel compensators connected together back to back can execute load voltage regulation and at the same time maintaining the grid current sinusoidal. With the extended significance on distribution generation and microgrids, the interest on UPQC has stimulated [20, 21]. Among the custom power devices, UPQC is able to keep the critical load (advanced medical instruments, elevator, digital communication networks etc.) protected from the voltage related power quality problems [22, 23].

The vital task in the controller part of the UPQC is reference signal generation. Several techniques are utilized to generate the reference signal. Among them, the frequency domain techniques and the time domain techniques are extensively utilized by the researchers. Due to the reduced computation requirements the time domain strategies are generally used in real time implementation. Instantaneous reactive power theory ( $p-q$ theory), theory of instantaneous symmetrical component and the synchronous reference frame theory (d-q theory) are widely utilized techniques.

In this paper, a three phase UPQC is introduced in terms of design and performance. In the series compensator a simple DVR circuit with PLL is used. On the other hand, the performance of the UPQC is enhanced by using the $\mathrm{d}-\mathrm{q}$ theory in the controller section of shunt compensator. Besides, a simple hysteresis controller-based series compensator is used. The main features of the proposed system are, a) the voltage and the current quality is maintained simultaneously and b) stability is ensured under several conditions of voltage harmonics, voltage sags/swells and unbalanced load. The proposed system outcome is analyzed substantially using MATLAB-Simulink software.

\section{RESEARCH METHODOLOGY}

The UPQC structure is displayed in Figure 1. The structure is constructed for a three-phase system. The UPQC model is designed with a back to back connection of a series compensator and a shunt compensator and a common DC-link which is shared by both the compensator. The series compensator operates as a controlled voltage source and compensate the voltage sags/swells for the grid. On the other hand, the shunt compensator acts as a controlled current source and compensate the harmonic current for the load. Inductor is used between the series compensator and the distribution system and same design is followed for the shunt compensator. The harmonics generated by the converter's switches are filtered using the ripple filters. A three-phase bridge rectifier is used as a non-linear load in the system.

\subsection{Design of UPQC}

\subsubsection{Voltage magnitude of DC-link}

The modulation depth and the phase voltage of the system gives the magnitude of DC-link voltage $V_{d c}$. The minimal voltage magnitude of the DC-link required to be twice or more than the per-phase voltage peak of the three-phase system [1] and formulated as,

$$
V_{d c}=\frac{2 \sqrt{2} V_{L L}}{\sqrt{3} m}
$$

Where, $V_{L L}$ is the grid line voltage and the depth of modulation $(\mathrm{m})$ is taken as 1 . Considering a line voltage of $415 \mathrm{~V}$, the needed minimum value DC-bus voltage is $677.7 \mathrm{~V}$. The DC-bus voltage is set at 1000 $\mathrm{V}$.

Int J Pow Elec \& Dri Syst Vol. 10, No. 4, Dec 2019 : 2231 - 2237 


\subsubsection{Series injection transformer}

The series compensator is installed between the grid and the load terminal utilizing three single phase isolation transformers attached in star across the inverter and connected in series with the grid lines. To obtain minimum harmonics with the series compensator, the modulation index needs to be kept at near unity. The rating of the each series transformer is $4 \mathrm{KVA}$. A RC filter with a small capacity is added across the series transformer's secondary side to remove the high switching ripple component in the inverter injected voltage.

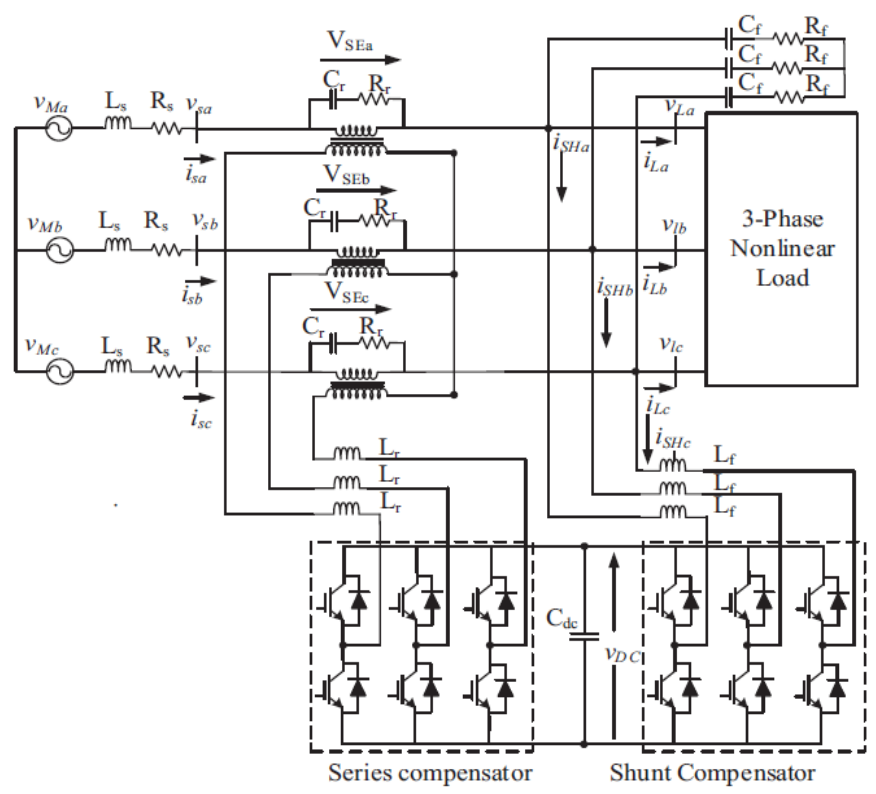

Figure 1. System Configuration UPQC.

\subsubsection{Inductor linked with series and shunt compensator}

The estimation of the inductor linked with the series and shunt compensator relies on DC-link voltage, switching frequency and ripple current. Inductor value [24] with the series compensator is expressed as,

$$
L_{r}=\frac{\sqrt{3} \times m V_{d c}}{12 a f_{s e} I_{r}}=\frac{\sqrt{3} \times 1 \times 1000}{12 \times 1.2 \times 10000 \times 2}=6 \mathrm{mH}
$$

Here, modulation index, $\mathrm{m}=1$, overloading factor, $\mathrm{a}=1.2$, switching frequency, $f_{\mathrm{se}}=10 \mathrm{kHz}, V_{d c}=$ $1000 \mathrm{~V}$ and $I_{r}$ is the ripple current of the inductor which is twenty percent of the grid current. And the value of the interfacing inductor [24] with the shunt compensator expressed as,

$$
L_{f}=\frac{\sqrt{3} \times m V_{d c}}{12 a f_{s h} I_{r, p p}}=\frac{\sqrt{3} \times 1 \times 1000 \times 1}{12 \times 1.2 \times 10000 \times 1.8}=6.7 \mathrm{mH}
$$

Here, inductor ripple current $I_{r, p p}$ is twenty percent of the rms value of the phase current of shunt compensator.

\section{CONTROL OF UPQC}

The shunt compensator and the series compensator are the major part of UPQC model. The shunt compensator mitigates the load harmonics and the load reactive power. The series compensator secures the load from the voltage disturbances created by the grid, for instance voltage harmonics, sags and swells. The series compensator acts as a controlled voltage source and inject the suitable voltage. 


\subsection{Control of series compensator}

Several compensation technique for the series controller is described in $[25,26]$. The injected voltage by the series compensator is maintained to be same phase with the grid in this project. The series compensator inject the minimum required voltage. In Figure 2, the series compensator configuration is displayed. To obtain the fundamental component of PCC, a Phase locked loop (PLL) is utilized to generate the reference waveform. The reference signals for the series compensator is obtained by comparing between the PCC voltage and the load voltage. Using these signals, the hysteresis controller produces appropriate gating signals for the voltage source converter (VSC) of the series compensator.

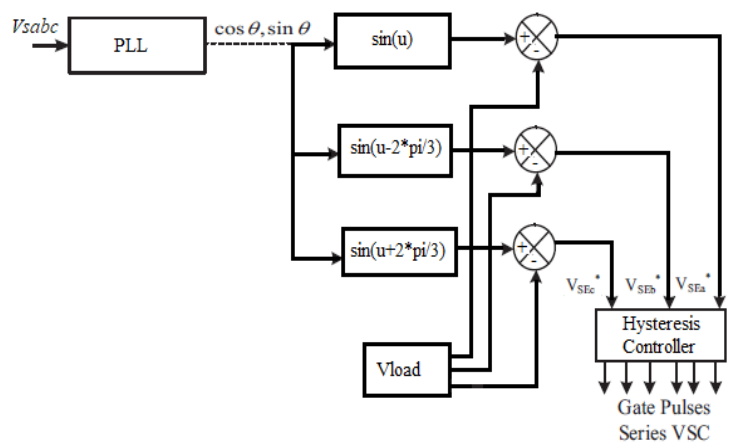

Figure 2. Control Structure of Series Compensator

\subsection{Control of Shunt Compensator}

The load current is compensated by the shunt compensator. DC-link voltage is stabilized by utilizing a PI-controller at the generated reference. The shunt compensator does the extraction of the fundamental element of the load current for the load compensation. The configuration of the shunt compensator is depicted in Figure 3. A PLL circuit is used to extract the phase and frequency data of the grid voltage and using these data the load currents of abc domain are converted to d-q-0 domain. The DC component $\left(I_{L d f}\right)$ is extracted from the d-element of the load current $\left(I_{L d}\right)$ by utilizing a low pass filter. The fundamental element of the DC component is represented in abc reference. The d-axis reference grid current $I^{*}{ }_{s d}$ is achieved using the following expression,

$$
I_{s d}^{*}=I_{L d f}-I_{l o s s}
$$

The reference grid current $\left(I^{*}{ }_{s d}\right)$ is transferred to abc domain. Gate pulses for voltage source inverter (VSI) are generated by using a hysteresis current controller. The hysteresis current controller compare the identified grid currents with the reference grid currents.

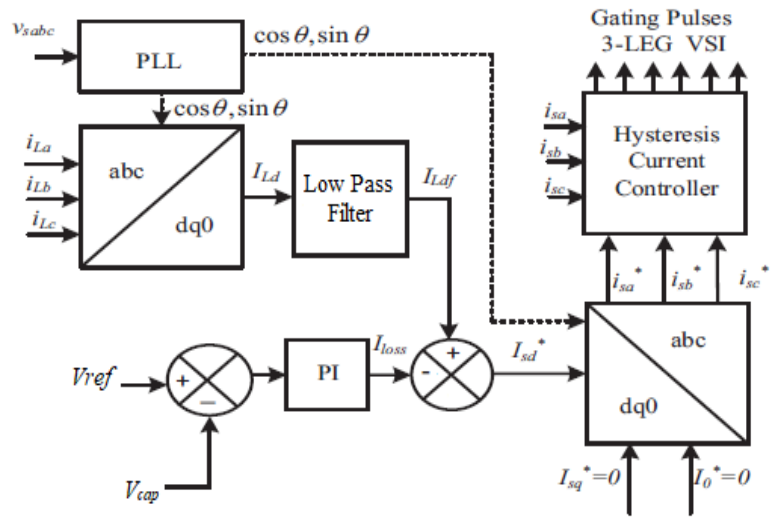

Figure 3. Control Structure of Shunt Compensator 


\section{SIMULATION STUDIES}

To examine the performances of UPQC for steady state and dynamic condition, MATLABSimulink software is used. A nonlinear three-phase bridge rectifier is considered for the simulation. The simulation run on several dynamic conditions for instance harmonics, swell and sag in the PCC voltage.

\subsection{Operation of UPQC at unbalanced PCC voltage}

The output results of UPQC is shown in Figure 4. The several output waveforms are PCC voltage $\left(V_{S}\right)$, load voltage $\left(V_{L}\right)$, series compensator voltage $\left(V_{S E}\right)$, DC-bus capacitor voltage $\left(V_{C}\right)$, grid current $\left(I_{S}\right)$, load current $\left(I_{L}\right)$ and shunt compensator current $\left(I_{S H}\right)$. The $5^{\text {th }}$ order and $7^{\text {th }}$ order harmonics are injected from the source between $0.1 \mathrm{~s}$ and $0.15 \mathrm{~s}$. There is a voltage sag of $0.5 \mathrm{pu}$ between $0.2 \mathrm{~s}$ and $0.25 \mathrm{~s}$ and $1.5 \mathrm{pu}$ of voltage swell occurred between $0.3 \mathrm{~s}$ and $0.35 \mathrm{~s}$. Grid voltage compensation has done by the series compensator under unbalanced PCC voltage conditions. The load voltage is maintained at the rated voltage condition. An appropriate voltage $V_{S E}$ is injected in opposite phase with the disturbances of grid voltage. Thus, the compensation for the grid voltage is obtained by the series compensator. Besides, an appropriate compensated current is generated and injected and a sinusoidal grid current is maintained by the shunt compensator.

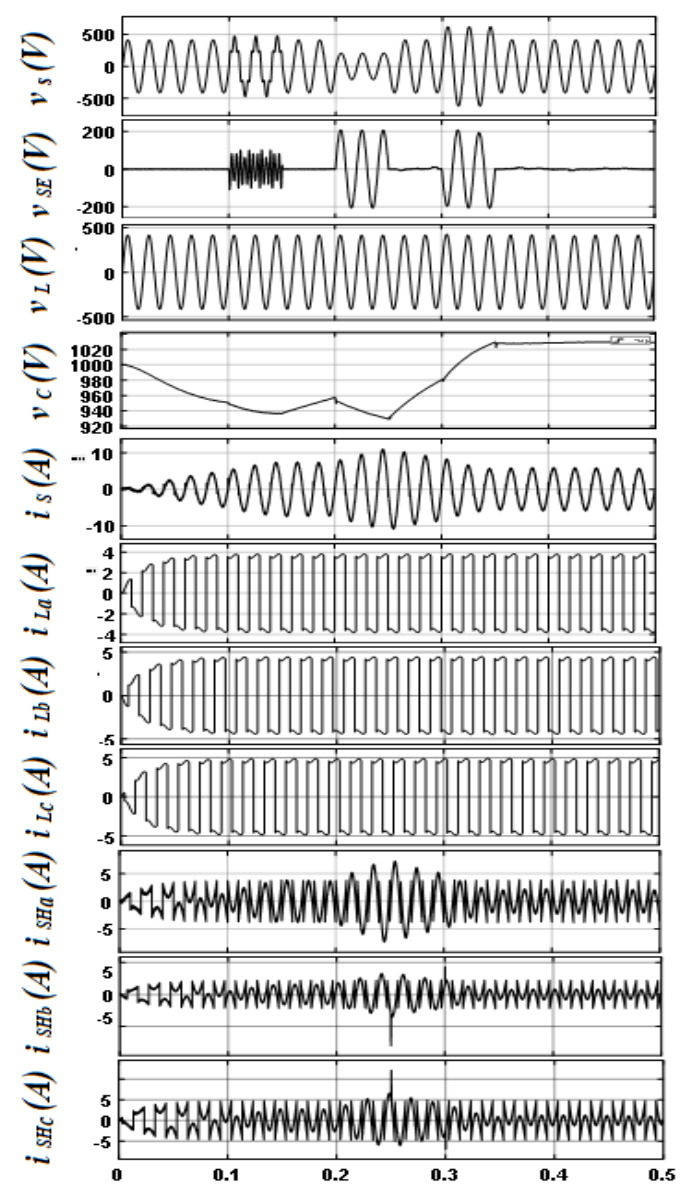

Figure 4. Operation of UPQC under voltage harmonics, swell and sag condition

\subsection{Operation of UPQC for unbalanced load}

The performance of UPQC is depicted in Figure 7 considering unbalanced load. The phase ' $a$ ' of the load is disconnected at $\mathrm{t}=0.4 \mathrm{~s}$. The sinusoidal grid current can be observed clearly from Figure 7 . The harmonics spectrum and the THD for the load current is displayed in Figure 5 and the harmonics spectrum and THD for the grid current is displayed in Figure 6. It can be noticed that the load current THD is $47.9 \%$ and the THD for the grid current is 3.59\%, therefore IEEE-519 standard [12] requirement is obtained. 


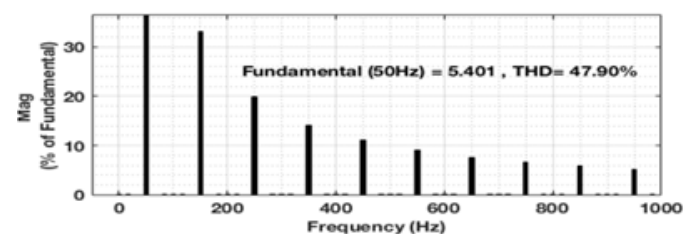

Figure 5. Harmonic spectrum and THD of the Load current

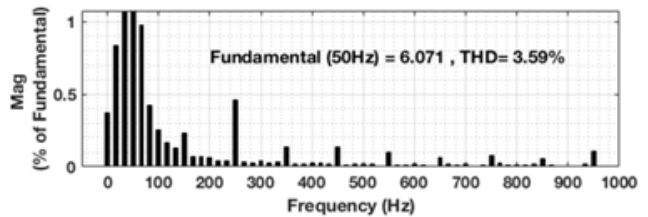

Figure 6. Harmonic spectrum and THD of the Grid current

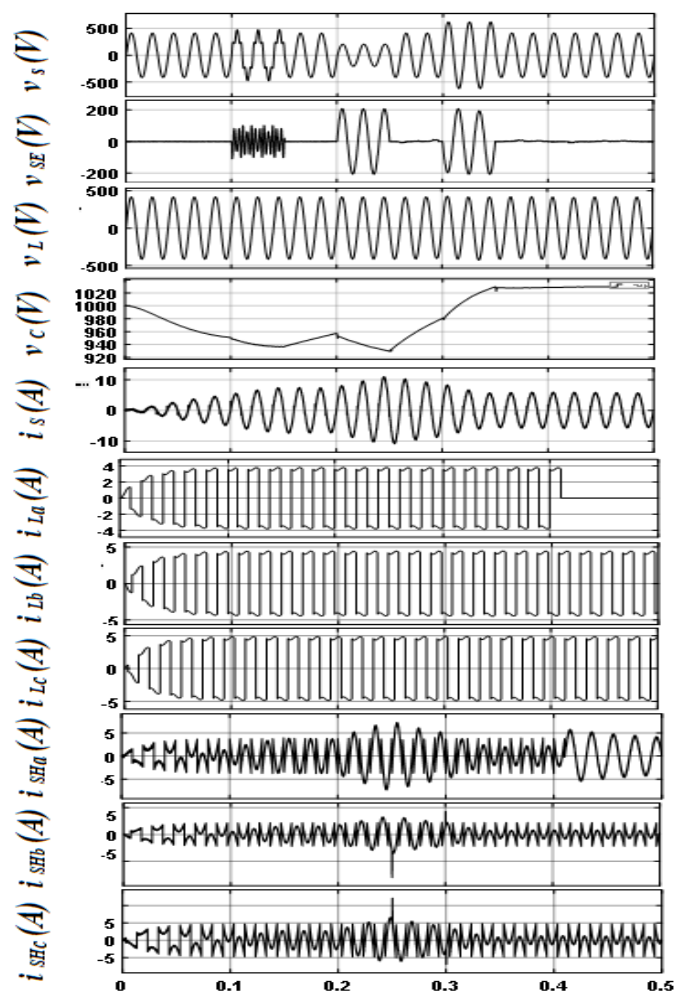

Figure 7. Operation of UPQC under voltage harmonics, swell and sag condition during unbalance load condition

\section{CONCLUSION}

The three-phase UPQC have been studied in terms of design and its dynamic operation under conditions of harmonics, voltage sags/swell and unbalanced load. It can be noticed that the harmonics are compensated which was created by nonlinear load and IEEE-519 standard for the grid current is maintained. The stability of the system is ensured under voltage harmonics, voltage sags/swells and unbalanced load. It can be concluded that UPQC integrated with the distribution generation can be a good solution to enhance the power quality of the modern distribution system.

\section{ACKNOWLEDGEMENTS}

This research was supported by the Long-Term Research Grant (LRGS), Ministry of Education Malaysia for the program titled "Decarbonization of Grid with an Optimal Controller and Energy Management for Energy Storage System in Microgrid Applications" with project code 600-IRMI/LRGS 5/3 $(001 / 2019)$. The authors would also like to acknowledge The Institute of Research Management \& Innovation (IRMI), Universiti Teknologi MARA (UiTM), Shah Alam, Selangor, Malaysia for the facilities provided to support on this research.

Int J Pow Elec \& Dri Syst Vol. 10, No. 4, Dec 2019 : 2231 - 2237 


\section{REFERENCES}

[1] B. Singh, A. Chandra and K. A. Haddad, Power Quality: Problems and Mitigation Techniques. London: Wiley, 2015.

[2] M. Bollen and I. Guo, Signal Processing of Power Quality Disturbances. Hoboken: John Wiley, 2006.

[3] P. Jayaprakash, B. Singh, D. Kothari, A. Chandra, and K. Al-Haddad, "Control of reduced-rating dynamic voltage restorer with a battery rage system," IEEE Trans. Ind. Appl., vol. 50, no. 2, pp. 1295-1303, March 2014.

[4] R. S. Vedam and M. S. Sarma, "Power quality: Var com ion in power systems," CRC Press 2009, Boca Raton, FL, USA.

[5] B. Singh, K. Al-Haddad and A. Chandra, "A review of active filters for power quality improvement", IEEE Transactions on Industrial Electronics, vol. 46, no. 5, pp. 960-971, 1999.

[6] A. Hamadi, S. Rahmani and K. Al-Haddad, "A Hybrid Passive Filter Configuration for VAR Control and Harmonic Compensation", IEEE Transactions on Industrial Electronics, vol. 57, no. 7, pp. 2419-2434, 2010.

[7] A. Bhattacharya, C. Chakraborty and S. Bhattacharya, "Shunt compensation", IEEE Industrial Electronics Magazine, vol. 3, no. 3, pp. 38-49, 2009.

[8] R. Sirjani and A. Rezaee Jordehi, "Optimal placement and sizing of distribution static compensator (D-STATCOM) in electric distribution networks: A review", Renewable and Sustainable Energy Reviews, vol. 77, pp. 688-694, 2017.

[9] R. Beres, X. Wang, M. Liserre, F. Blaabjerg and C. Bak, "A Review of Passive Power Filters for Three-Phase GridConnected Voltage-Source Converters", IEEE Journal of Emerging and Selected Topics in Power Electronics, vol. 4, no. 1, pp. 54-69, 2016.

[10] J. Ringwood and S. Simani, "Overview of modelling and control strategies for wind turbines and wave energy devices: Comparisons and contrasts", Annual Reviews in Control, vol. 40, pp. 27-49, 2015.

[11] K. Ahmed, S. Finney and B. Williams, "Passive Filter Design for Three-Phase Inverter Interfacing in Distributed Generation", 2007 Compatibility in Power Electronics, 2007.

[12] "IEEE recommended practices and requirements for harmonic control in electrical power systems," IEEE Std 5191992, pp. 1-112, April 1993.

[13] M. Farhoodnea, A. Mohamed and H. Shareef, "A comparative study on the performance of custom power devices for power quality improvement", 2014 IEEE Innovative Smart Grid Technologies - Asia (ISGT ASIA), 2014.

[14] C. Kumar and M. Mishra, "Operation and Control of an Improved Performance Interactive DSTATCOM", IEEE Transactions on Industrial Electronics, vol. 62, no. 10, pp. 6024-6034, 2015.

[15] S. B. Karanki, N. Geddada, M. K. Mishra and B. Kumar, "A Modified Three-Phase Four-Wire UPQC Topology with Reduced DC-Link Voltage Rating", IEEE Transactions on Industrial Electronics, vol. 60, no. 9, pp. 35553566, 2013.

[16] K. Somsai, "Controller Design of UPQC for Enhancing Power Quality in Distribution System", International Journal of Power Electronics and Drive Systems (IJPEDS), vol. 9, no. 4, p. 1591, 2018.

[17] B. Slimane, A. Othmane and A. Abdelkader, "Unified Power Quality Conditioner Supplied by Fuel Cell System Via SEPIC Converter", International Journal of Power Electronics and Drive Systems (IJPEDS), vol. 10, no. 1, p. $178,2019$.

[18] A. Javadi, A. Hamadi, L. Woodward, and K. Al-Haddad, "Experimental investigation on a hybrid series active power compensator to improve power quality of typical households," IEEE Trans. Ind. Electron., vol. 63, no. 8, pp. 4849-4859, Aug 2016.

[19] A. Javadi, L. Woodward and K. Al-Haddad, "Real-Time Implementation of a Three-Phase THSeAF Based on a VSC and a P+R Controller to Improve the Power Quality of Weak Distribution Systems", IEEE Transactions on Power Electronics, vol. 33, no. 3, pp. 2073-2082, 2018.

[20] S. K. Khadem, M. Basu, and M. F. Conlon, "Intelligent islanding and seamless reconnection technique for microgrid with upqc," IEEE Journal of Emerging and Selected Topics in Power Electronics, vol. 3, no. 2, pp. 483492, June 2015.

[21] J. M. Guerrero, P. C. Loh, T. Lee and M. Chandorkar, "Advanced Control Architectures for Intelligent Microgrids-Part II: Power Quality, Energy Storage, and AC/DC Microgrids", IEEE Transactions on Industrial Electronics, vol. 60, no. 4, pp. 1263-1270, 2013.

[22] A. Ghosh and G. Ledwich, "Compensation of distribution system voltage using dvr," IEEE Trans. Power Del., vol. 17, no. 4, pp. 1030-1036, Oct 2002.

[23] D. D, S. Bugata and K. J, "A control strategy on power quality improvement in consumer side using custom power device", Indonesian Journal of Electrical Engineering and Computer Science, vol. 15, no. 1, p. 80, 2019.

[24] S. Devassy and B. Singh, "Design and Performance Analysis of Three-Phase Solar PV Integrated UPQC", IEEE Transactions on Industry Applications, vol. 54, no. 1, pp. 73-81, 2018.

[25] A. Sadigh and K. Smedley, "Review of voltage compensation methods in dynamic voltage restorer (DVR)", 2012 IEEE Power and Energy Society General Meeting, 2012.

[26] A. Rauf and V. Khadkikar, "An enhanced voltage sag compensation scheme for dynamic voltage restorer," IEEE Trans. Ind. Electron., vol. 62, no. 5, pp. 2683-2692, May 2015. 